\title{
Modeling Referential Actions in 6- to 18-Month-Old Infants: A Precursor to Symbolic Understanding
}

\author{
Tara C. Callaghan, Philippe Rochat, Tanya MacGillivray, and Crystal MacLellan
}

\begin{abstract}
Social precursors to symbolic understanding of pictures were examined with 100 infants ages 6, 9, 12, 15, and 18 months. Adults demonstrated 1 of 2 stances toward pictures and objects (contemplative or manipulative), and then gave items to infants for exploration. For pictures, older infants (12, 15, and 18 months) emulated the adult's actions following both types of demonstration trials. For objects, infants did not emulate actions following either stance at any age. The findings suggest that infants enlist their imitative learning skills in the context of learning the conventions of action on pictorial symbols. The data are interpreted as pointing to the importance of social learning in developing an understanding of the referential function of pictorial symbols.
\end{abstract}

The insight that symbolic artifacts have a referential function is a major developmental accomplishment of early childhood. Although much research has focused on the development of language symbols, relatively little has investigated pictorial symbols. For pictorial symbols, a core theoretical goal is accounting for development of the critical insight that pictures are representational artifacts and not simply interesting objects in their own right. The symbolic function of pictures may seem obvious to adults; however, a growing body of literature suggests that it is not obvious for young children (Callaghan, 1999, 2003; DeLoache, 2002; DeLoache \& Burns, 1994). Instead, the research indicates that the development of symbolic understanding of pictures is a lengthy process that may span a lifetime (Callaghan, 2003; Callaghan \& Rochat, 2003, 2004; Callaghan, Rochat, Lerikos, MacDougall, \& Court, 2004; DeLoache, Pierroutsakos, \& Troseth, 1996; Liben, 1999; Robinson, Nye, \& Thomas, 1994; Rochat \& Callaghan, in press; Thomas, Nye, \& Robinson, 1994). Exactly how and when understanding of the representational function of pictures first develops, and the foundations from which it develops, have been topics of recent interest to several researchers.

Callaghan (2000; Callaghan \& Rochat, 2003; Callaghan, Rochat, Lerikos et al., 2004) distinguishes

Tara C. Callaghan, Department of Psychology, St. Francis Xavier University; Philippe Rochat and Tanya MacGillivray, Department of Psychology, Emory University; Crystal MacLellan, Department of Psychology, University of Alberta.

This research was supported by the Natural Sciences and Engineering Research Council of Canada. The authors thank the infants and parents who volunteered for these experiments.

Correspondence concerning this article should be addressed to Tara Callaghan, Department of Psychology, St. Francis Xavier University, P.O. Box 5000, Antigonish, N.S., Canada, B2G 2W5. Electronic mail may be sent to tcallagh@stfx.ca. between use of pictorial symbols in a variety of picture symbol tasks and conceptual understanding of pictorial symbols. The first is easily measured and appears relatively early, and the second is both difficult to measure and develops much later. The first indication that children use pictures symbolically comes sometime around their third birthday when they can choose the object depicted in a drawing from a pair of choice objects (Callaghan, 1999, 2000; Callaghan \& Rankin, 2002), search for an object hidden in a large room after being presented with a pictorial symbol of the object (DeLoache, 1991; DeLoache \& Burns, 1994), and choose a picture that corresponds to the imagined outcome of a transformative action (Harris, Kavanaugh, \& Dowson, 1997). Use of pictorial symbols in these tasks may reflect conceptual understanding of the representational function of pictures; however, it does not necessarily indicate understanding at such a level (Perner, 1991). For example, children may make their responses in all of these tasks on the basis of a perceptual match between the picture and its referent, or on a "reading" of the pictorial symbols, as when children use the verbal label of the referent to complete a picture symbol task (Callaghan, 2000). Thus, exactly what the child's concept of a picture and its function consists of is difficult to discern from early success on picture symbol tasks.

The findings from two studies designed to measure understanding of the referential function of pictures suggest that this conceptual level of understanding may develop relatively late. In one study, children were asked to judge attributes of an artist from their pictorial traces (Callaghan \& Rochat, 2003), and in another they were asked to predict

(C) 2004 by the Society for Research in Child Development, Inc. All rights reserved. 0009-3920/2004/7506-0008 
where another person would look for objects hidden inside a box when pictorial labels on the boxes had been deceptively switched (Callaghan, Rochat, Lerikos et al., 2004). It was only around their fifth birthday that children understood that a picture indicated something about the mental state of the artist, and around their seventh birthday that they understood that others use pictures to indicate what is inside a box. The current study ventured far earlier in the developmental trajectory, before the onset of picture symbol use and conceptual understanding, and asked what are the foundations from which this understanding develops.

Recent theories suggest that pictorial symbol understanding is built on basic perceptual/cognitive and action foundations that infants and toddlers bring to the symbolic context. In one such theory, DeLoache (2002) suggests that analogical reasoning and the appreciation of perceptual differences and similarities between symbols and referents precede the development of symbolic insight for replica and pictorial symbols. In another theory, Liben (1999) proposes that in addition, representational strategies must be accessed by children for full understanding of external spatial representations. In a third theory, Callaghan and colleagues (Callaghan, 2003; Rochat \& Callaghan, in press) claimed that the mechanisms of perceptual differentiation, perceptual categorization, and analogical reasoning are important precursors. The argument is that these mechanisms allow infants to appreciate aspects of the picture symbol-referent relation that are foundations for the eventual, critical insight that the relation is representational. Differentiation skills allow infants to distinguish between the two-dimensional symbol and three-dimensional referent, categorization skills enable infants to eventually group those two-dimensional items into a special type of cultural artifact, and analogical reasoning skills facilitate the appreciation of the same-but-different relation between those special two-dimensional artifacts and their referents. The current study focused on a fourth mechanism highlighted by Callaghan and colleagues - that of social learning through modeling what others do. In the context of pictures, it was proposed that infants follow the lead of others when deciding how to act on pictures, a special type of cultural artifact. The propensity of others to scaffold development by demonstrating referential actions for infants, as well as the capacity of infants to model the actions of others, are two components important to this social learning mechanism.

The supporting role of others in symbolic development has long been proposed in the domain of language (Wood, Bruner, \& Ross, 1976) and is demonstrated by the link between joint attention episodes and language acquisition (Tomasello \& Farrar, 1986). Whereas there are important differences between language and other types of symbols such as pictures, those differences do not preclude the possibility that there are also similarities in the processes underlying symbolic understanding across domains (see Sigel, 1978, for arguments relevant to this point). Callaghan and colleagues have begun to examine the role of social supports in the domain of visual symbols. When young children were engaged in social interactions about the symbolic function of pictures (Callaghan, 1999; Callaghan \& Rankin, 2002), children's use of others' pictorial symbols and productions of their own pictorial symbols improved. In the first study (Callaghan \& Rankin, 2002), experimenters highlighted the symbolic relation between pictures and their referents by having the child hold an object while the experimenter drew it and then placed the object on top of its picture, and in the second (Callaghan, 1999) children used their own pictures to show an experimenter which object to choose. Control groups confirmed that when adults engaged children in interaction with these same objects but without highlighting the symbolic function, there was no improvement. Taken together, the findings suggest that when social interactions are about the referential nature of words or pictures, symbolic functioning is facilitated.

The claim that social interactions are an important mechanism in conceptual understanding of visual symbols is corroborated by two recent studies. One was a naturalistic study in which parents read a picture book containing challenging changes of spatial perspective across pages with their 3- and 5year-old children (Szechter \& Liben, 2004). In this study, only when parents engaged in behaviors that highlighted the representation of these spatialgraphic challenges, and they did so at both ages, was children's performance better on other spatial representation tasks. In a related study, Troseth (2003) showed that when parents used live video in the home over a 2-week period to demonstrate the link between reality and the televised image, toddlers exposed to the training performed better than controls in subsequent tasks that used video or pictures to symbolize hiding places in standard hiding tasks.

When an adult provides support to a novice symbol user, such as the support given in the training and naturalistic studies just mentioned, it is clear that infants and children need to have developed mechanisms that enable them to respond to that support. One potential mechanism is the ability to infer communicative intentions from the actions of 
others, a mechanism thought to be critical in the domain of language acquisition (Tomasello, 1999, 2001). Another potential mechanism is the ability to model the actions of others, in particular, referential actions.

There is evidence that young infants are sensitive to basic aspects of the intentions of adults who act on objects in the world and that older infants begin to discern the more subtle communicative intentions of adults in the flow of actions found in social exchanges. Inferring intention from actions appears to develop rapidly between 12 and 24 months of age. Woodward and Guajardo (2002) report that 12- but not 9-month-old infants construe pointing events as relations between an actor and object, and that their construal of others' pointing was correlated to the onset of their own pointing behavior. Woodward showed a similar developmental trajectory for understanding of the relation between a person's gaze and the object of that gaze (Woodward, 2003), and between a person's grasp and the object of the grasp (Woodward, 1999). What these findings suggest is that by approximately 12 months of age infants have an important first component of intentional understanding, that is, the understanding that intentional actions are object directed.

The importance of this understanding to symbolic domains, especially language learning, has been demonstrated by other researchers. Baldwin (1991) showed that as early as 16 to 18 months infants use eye gaze to determine what object an adult is referring to in a naming game, and when that cue is unavailable (Baldwin, 1993), infants avoid making an association between the word and direction of the adult's gaze. Tomasello and colleagues reported that late in their 2nd year infants make inferences about adults' intentions even in the absence of any distinctive cues such as eye gaze and use these inferences to facilitate novel word learning (Akhtar, Carpenter, \& Tomasello, 1996; Akhtar \& Tomasello, 1996; Tomasello, 2001; Tomasello \& Akhtar, 1995; Tomasello \& Barton, 1994). It is likely that the ability to construe intention in action is based on a more basic foundation of detecting structure in human action and that this foundation may provide the support infants need to infer intention from that human action (Baird \& Baldwin, 2001; Baldwin, Baird, Saylor, \& Clark, 2001). For example, when infants watch videotapes of natural actions (e.g., an adult picking up a towel from the floor and placing it on a rack) they are sensitive to whether a pause in the action is inserted randomly or at an intentional boundary (i.e., just before or after the completed action).
The other potential mechanism that enables infants to respond to the supports of others is the powerful imitative learning mechanism available during infancy. Even at birth, infants model the facial expression of others (Field, Woodson, Greenberg, \& Cohen, 1982; Meltzoff \& Moore, 1977, 1989, 1999) and by 9 months are imitating novel actions on novel objects (Meltzoff, 1988). By 12 months infants also tune into the adult's emotional cues and use those cues to direct their action in ambiguous social situations (Baldwin \& Moses, 1996; Campos \& Stenberg, 1981). Infants at 18 months successfully produced intended actions of the adult, even though they had never seen the action successfully produced (Meltzoff, 1995).

Taken together, these studies of language, intentions, and imitation suggest that infants actively search for meaning in the communicative actions of others in their social world and that one of the first steps in the construction of meaning is acting like others do when encountering things that are not yet known. Piaget (1962) was the first to suggest that imitation played an important role in the development of symbolic actions, in particular, play. Others have argued that it plays a central role in language development (Carpenter, Nagell, \&Tomasello, 1998; Kuhl \& Meltzoff, 1982; Nadel, Guerini, Peze, \& Rivet, 1999). The current study applied this line of reasoning to pictorial symbols. We proposed that one of the vehicles infants may use to construct their knowledge of pictorial symbols is modeling the actions others take toward those symbols, and it suggested that infants may model those actions even before they have a conceptual understanding of the referential function of pictorial symbols. That is, they may have an early, action-based knowledge of pictorial symbols that provides a foundation for later, conceptually based knowledge. Thus, the main goal of the current study was to clarify the role modeling has on the development of the conventions of action toward pictorial symbols.

To accomplish this, we modeled actions that were either contemplative or manipulative with respect to both pictures and objects, and then gave those items to infants to see how they acted on them. For example, in one condition we took a contemplative stance toward pictures (held up the picture, pointed to it, looked between the infant and the picture) and objects (held up the object, pointed to it, looked between the infant and the object). In a second condition, we took a manipulative stance toward pictures (jiggled and shook the picture in front of the infant) and objects (jiggled and shook the object in front of the infant). We chose these action stances to highlight 
two potential aspects of items: the referential function (i.e., in the contemplative stance) and the object status (i.e., in the manipulative stance). In separate conditions across participants, we applied both stances to both types of items (i.e., pictures and objects) to contrast the propensity of infants to model actions when the item was a relatively novel, symbolic artifact compared with a relatively familiar, graspable toy.

We did not expect infants in this age range (6 to 18 months) to imitate the exact form and sequences of actions we took toward the items for two reasons: They were complex sequences of actions that would likely be beyond the limits of most infants' motor coordination in this age range, and we designed the sequences to ensure that the referential versus manipulative goals were salient for infants. Thus, we expected infants to reach the goal demonstrated by the adult through a variety of means (emulate) rather than through precise mimicking of the adult's actions (imitate). For example, emulation of the referential goal (contemplative stance) would be indicated by infants looking at the picture while holding it up, sliding it toward them for a closer look with or without maintaining touch of the picture, or looking at it and then showing it to the adult. In contrast, imitation of the referential goal would be seen if infants held the picture up and pointed to it while looking between the adult and the picture. There is increasing support in the literature for the idea that infants will emulate rather than imitate actions of the type demonstrated in the current study (Gergely, Bekkering, \& Kiraly, 2002; Gergely, Nadasdy, Csibra, \& Biro, 1995; see Tomasello, Kruger, \& Ratner, 1993, for further discussion of the distinction between emulation and imitation).

We also expected infants to model selectively the actions we took toward the different types of items. Based on social referencing research (see Campos \& Stenberg, 1991, for a review), we reasoned that only when infants were unsure of what to do with an item would they consult others for information and subsequently model their actions. Although infants may occasionally be exposed to photographs, it is highly unlikely that they would be familiar with the laminated versions used here or that they would have been allowed to manipulate them freely. In contrast, it is highly likely that the attractive, graspable toys used here were similar to toys infants have directly experienced at this age (Rochat, 1989, 2001). Thus, we reasoned that infants would be more likely to model the stances we took toward pictures than those taken toward the infant toys depicted in those pictures. Support for this reasoning comes from a study giving pictures and objects to infants between 6 and 18 months of age for exploration (Callaghan, Rochat, MacGillivray, \& MacLellan, 2004). Beginning at 9 months of age, infants were found to look significantly more often toward the experimenter when given pictures $(M=2.0)$ as compared with objects $(M=1.38)$ to explore. We also expected that younger infants would be less likely than older infants to model the stance. In particular, infants should begin to model the contemplative stance around 12 months, given that the contemplative stance was meant to portray an intent to communicate about the item, and the developmental window on sensitivity to communicative intentions appears to be 12 to 24 months.

To summarize, the idea guiding the present research is that an early step in infants' development of conceptual understanding of the symbolic function of pictures is noticing and modeling how others in their culture act toward pictures. We view the actions taken by infants following a model to be precursors to later conceptual understanding, actions that are themselves devoid of referential meaning but that provide a foundation on which to build that understanding.

\section{Method}

\section{Participants}

Participants were 100 infants: 25 at 6 months ( $M=6.7$ months, range $=5.9$ to 7.2 months $), 21$ at 9 months $(M=9.5$ months, range $=8.8$ to 10.7 months), 20 at 12 months $(M=12.3$ months, range $=$ 11.3 to 12.8 months), 18 at 15 months $(M=15.4$ months, range $=14.5$ to 16.1 months), and 16 at 18 months $(M=18.2$ months, range $=17.7$ to 18.8 months). Ten infants were excluded from the study because of fussing (8) and experimenter error (2). Half of the infants from each age group were randomly assigned to the contemplative and manipulative stance conditions. There were approximately even numbers of male and female infants assigned to each of the conditions at each age. Infants were recruited through phone calls to parents from diverse racial and socioeconomic status environments who had indicated their interest in participating in infancy studies. The resulting sample was predominantly Caucasian and middle class.

\section{Materials}

The materials were 12 plastic infant toys (approximately $10 \mathrm{~cm}$ in diameter) and 12 high-quality, 


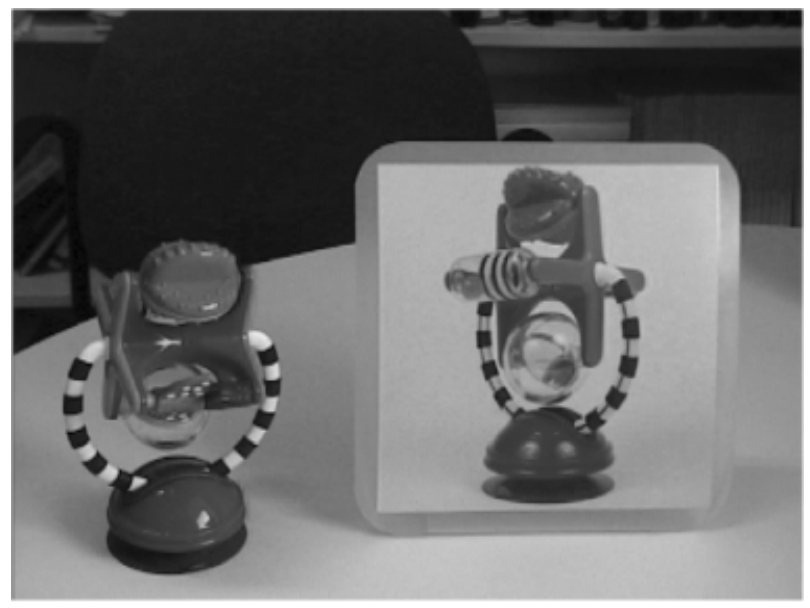

Figure 1. Sample object and picture.

life-size color photographs of those toys $(20 \mathrm{~cm}$ diameter, with the object centered), for a total of 24 items. Figure 1 presents a sample toy and photograph. Other toys were similar to these. Pictures were laminated and rounded at the edges. Both pictures and objects were safe for exploration by infants.

\section{Procedure}

Infants sat on their mothers' laps during the experiment, centered in front of a table. Mothers were asked to refrain from interacting with their infants during the session, and all complied with this request. A video camera positioned behind and to the left of the experimenter recorded the entire session. The experimenter, who sat directly across the table from the infants, presented items to the infant in a predetermined, counterbalanced order, and kept items out of sight between trials.

Infants were exposed to demonstrations of only one stance, according to their stance condition. For each infant this stance (i.e., either contemplative or manipulative) was demonstrated for both pictures and objects. The 12 trials for pictures were blocked separately from the 12 trials for objects, and the order of blocks was counterbalanced across infants. Preliminary analyses determined that there were no block order effects; therefore, this variable was not considered in the main analyses that follow. For each type of item (pictures or objects), the 12 blocked trials consisted of 8 modeling-alone trials ( 1 for each of 8 different pictures or objects) followed immediately by 4 modeling-plus-exploration trials ( 1 for each of 4 different pictures or objects). Thus, in each block infants saw 8 demonstrations of the action in modelingalone trials, where the experimenter modeled the stance but did not place the item in front of the infant for exploration, before being able to act on the item themselves in the modeling-plus-exploration test trials, where the experimenter modeled the stance and after each of the 4 demonstrations placed the item in front of the infant for $15 \mathrm{~s}$ of exploration. Preliminary analyses of order effects in the sequence of 4 test trials determined that order did not influence infants' actions; therefore, this variable was not included in the main analyses that follow.

Thus, across the picture and object blocks of trials there was a total of 24 trials ( 16 modeling alone and 8 modeling plus exploration). The 8 modeling-plusexploration trials (4 for pictures, 4 for objects) constituted the test trials. When the infants were exploring the items, the experimenter watched them with a pleasant demeanor but did not give any feedback on their actions.

The main thrust of the actions in the contemplative stance was to highlight the referential nature of picture contemplation (see Figure 2 for photographs depicting both stances). The experimenter communicated her referential intentions by holding the item up and to her right, and pointing to it while twice looking back and forth between the item and the infant. To ensure that the infant attended to her, the experimenter got the infant's attention by saying his or her name, then immediately said "look" just before she turned her head to look and point at the item. Then she turned back toward the infant, said "look" once more before turning a second time toward the item held up. In the manipulative stance, the experimenter communicated her exploratory intentions by holding the item centered in front of the infant, just out of reach, and then jiggled and shook the item in a vertical direction, first one side then the other. As in the contemplative stance, the experimenter said the infant's name to get his or her attention, and said "look" twice in between bouts of jostling the item. The entire session lasted approximately 15 to $20 \mathrm{~min}$.

\section{Results}

\section{Scoring and Analyses}

To assess whether infants modeled the experimenter's actions (i.e., contemplative or manipulative stance), infants' first actions taken toward items on each of the eight test trials (i.e., four for pictures, four for objects) were coded from videotaped data. Interrater reliability based on $25 \%$ of the data was high ( $\kappa s=.86$ for looking and .88 for manual exploration). Infants' first actions were measured because they reflect the infant's immediate response to the modeled stance, separate from any potentially 

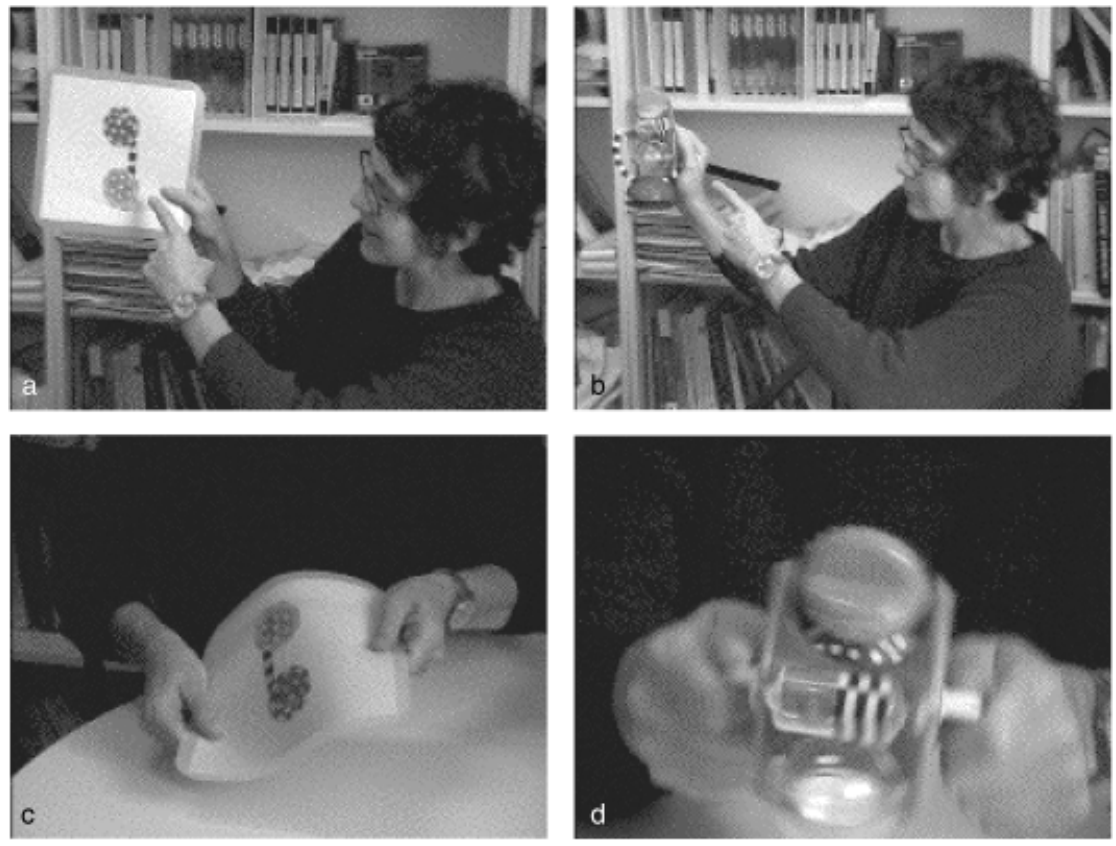

Figure 2. Photographs of the contemplative stance taken toward pictures (a) and objects (b), and the manipulative stance taken toward pictures (c) and objects (d).

confounding effects that measuring an entire sequence of actions may have.

After extensively coding all first actions taken toward items, we classified first actions on each trial into two types that incorporated the majority of first actions infants took toward the items and that captured the contemplative versus manipulative distinction inherent across the two modeled stances. These categories were looks and manual exploration. Actions toward the item were coded as looks if the infant's eyes were focused on the item for at least $3 \mathrm{~s}$ before manual behavior began. The criteria of $3 \mathrm{~s}$ was chosen to eliminate fleeting glances that were too short to allow for contemplation, and the criteria of a pause in manual action was added to differentiate between contemplation and visually guided manual exploration of the item. Looks were taken to indicate the adoption of a contemplative stance toward the item on the part of the infant. Manual exploration included any grasping, rubbing, mouthing, banging, slapping, or pushing of the item or any part of the item. For pictures this included grasping the depicted object, which was rare. A tendency toward manual exploration was taken to indicate the adoption of a manipulative stance on the part of the infant.

\section{Modeled Stance: Contemplative Versus Manipulative}

Looks. The data for the first analysis of variance were the number of looks across the four test trials for each of four conditions: picture - contemplative stance, picture-manipulative stance, object-contemplative stance, object-manipulative stance. These data were analyzed in a 5 (ages) $\times 2$ (stance: contemplative, manipulative) $\times 2$ (item: picture, object) mixed analysis of variance ANOVA. The three-way interaction of Age $\times$ Stance $\times$ Item, $F(4$, $90)=3.15 p<.05$, presented in Figure 3, qualified all other effects.

A posteriori tests (least significant difference; see Kirk, 1968, for rationale) showed no significant differences in looks as a function of stance or item for infants between the ages of 6 and 12 months; however, looks to pictures for 15- and 18-month-olds were greater following the contemplative as compared with the manipulative stance. In contrast, looks to objects were not influenced by stance at any age. Thus, stance influenced looks only for pictures and only for the older infants (15 and 18 months). Other significant effects included the main effects of stance, $F(1,90)=6.82, p<.01$, and item, $F(1$, $90)=23.75, p<.001$, and the Age $\times$ Item interaction, $F(4,90)=3.63, p<.01$, and Stance $\times$ Item interaction, $F(1,90)=5.95, p<.05$.

Manual exploration. The data for the second ANOVA were the number of manual explorations across the four test trials for each of the four conditions: picture-contemplative stance, picture-manipulative stance, object-contemplative stance, object-manipulative stance. These data were 

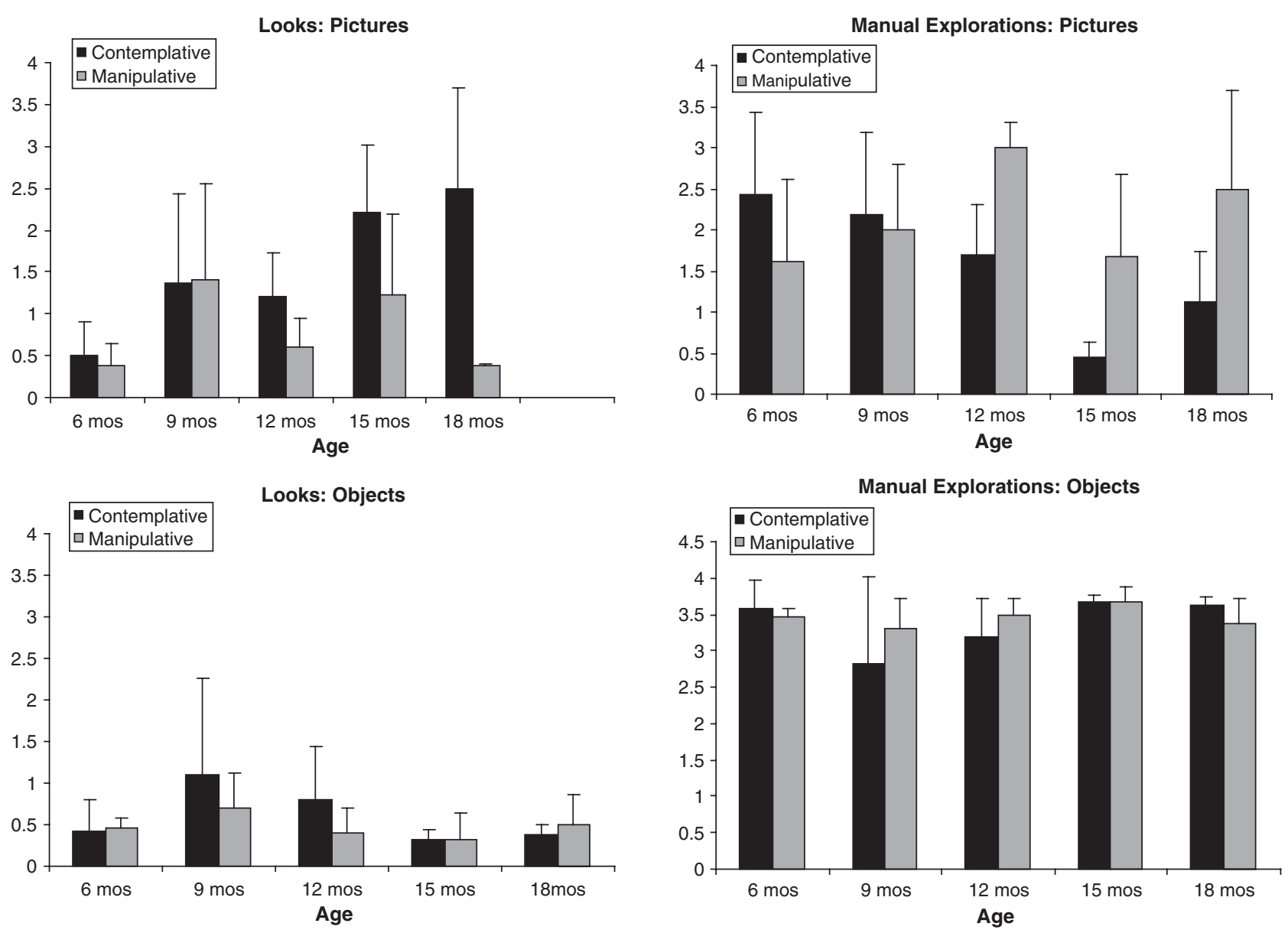

Figure 3. Mean number (out of 4) of looks to pictures (top) and objects (bottom) as a function of stance. Error bars reflect standard deviations for the groups.

analyzed in a 5 (ages) $\times 2$ (stance: contemplative, manipulative) $\times 2$ (item: picture, object) mixed ANOVA. Once again, a three-way interaction qualified all other effects. The three-way interaction of Age $\times$ Stance $\times$ Item, $F(4,90)=2.87, p<.05$, is presented in Figure 4. A posteriori tests of this interaction (least significant difference) revealed no differences in manual explorations as a function of stance for 6- and 9-month-olds for either pictures or objects. The amount of manual exploration for 12-, 15-, and 18-month-olds depended on both stance and item. For all three ages, manual explorations of pictures were greater following the manipulative versus the contemplative stance, whereas manual explorations of objects were high and not influenced by stance at any age. Thus, stance affected the amount of manual exploration only for pictures and only for older infants (12, 15, and 18 months). Other significant effects included the main effect of item, $F(1$, $90)=115.87, p<.001$, and the Age $\times$ Item interaction, $F(4,90)=4.29, p<.01$.

Figure 4. Mean number (out of 4) of manual explorations to pictures (top) and objects (bottom) as a function of stance. Error bars reflect standard deviations for the groups.

\section{Discussion}

Pictorial symbols pervade the environments of infants and young children, and are a popular mode of symbolism for young children, as evidenced by preschoolers' penchant for making representational drawings. The range of complexity in the meaning inherent in the pictorial symbols of Western culture is vast - from the picture of a crayon on a crayon box to Picasso's Guernica-and the need for social transmission to achieve full symbolic understanding is readily apparent, especially for the more complex symbols. But even for the simpler symbols, research suggests that novices entering the world of visual symbol use and production benefit from social support from more experienced symbol users. Social interaction using pictorial symbols as props has become increasingly popular in Western cultural settings and at increasingly younger ages with the advent of infant-directed picture books. But exactly what that interaction is about has implications for its 
impact on developing understanding of pictorial symbols. When it is about the referential nature of pictures, social interaction has been found, both in laboratory and naturalistic studies, to facilitate development of the insight that pictures have a referential function with fledgling symbol users (Callaghan, 1999; Callaghan \& Rankin, 2002; Szechter \& Liben, 2004; Troseth, 2003). In the current study we explored how infants respond to such supportive social interchanges with pictorial symbols and proposed that one of the foundations infants bring to these exchanges is the propensity to model what others do with unfamiliar objects. In particular, we proposed that infants' ability to model what others do with pictures is potentially one of the foundations, an action-based springboard, from which they subsequently launch a more conceptually based knowledge of the referential function of pictures.

The results of this study suggest that beginning around 12 months of age, infants were inclined to model the actions we demonstrated toward pictorial symbols, but not those directed toward the toys depicted in those symbols. One mechanism we believe is operating is social referencing. We expected a selective modeling of actions with pictures and not objects on the basis of findings in social referencing research and in previous research in our own lab using similar stimuli (Callaghan, Rochat, MacGillivray et al., 2004). The tendency to refer to others' actions for information about action conventions peaks around 12 months of age. Although the infants in this study surely had prior exposure to other types of pictures, we are confident that the pictorial symbols, and the manipulative stance used with pictures, were unfamiliar to them. Photographs are typically presented in books and shown, not given as in this study. In contrast, the objects we used were attractive, manipulable toys specially designed for infants and for direct manipulation, likely similar to toys in the infants' homes. These facts lead to an interesting observation; when we modeled actions, those actions were conventional for that item (e.g., contemplating pictures, manipulating objects) or less conventional (e.g., manipulating pictures, contemplating objects). Regardless of the conventionality of the action, between 12 and 18 months infants modeled what we did with pictures but not objects. We believe this suggests that in this age range infants are still not certain of the conventions of actions with pictorial symbols and may be still open to learning about the conventions. It is not surprising that social referencing is strong even late in infancy; there are still social situations of ambiguity that will even lead an adult to consult others for instruction on how to behave.
Why did younger infants not model referential actions on pictures? The answer may lie in a second mechanism we believe is relevant to adopting conventional actions toward pictorial symbols: reading the intentions in others' actions. We propose that young infants are not yet adept at inferring intentions from the action sequences of others, an ability that has been found to be strong in the 12- to 24month age range. Although our current research was not designed as a direct test of infants' ability to infer intentions in the pictorial symbol domain, we agree with the arguments advanced by others that inferring intentions is a critical skill infants bring to the context of symbolic development (Baldwin, 1991, 1993; Tomasello, 2001). Additional research that directly manipulates communicative intentions in the context of pictorial symbols is needed to confirm the importance of this infant skill to pictorial symbol understanding and its link to infants' propensity to model referential actions on pictures.

How do our findings compare with what infants do with pictures and objects outside of a modeling context? In related research using the same pictures and objects, we have shown that across the same age range (6 to 18 months) infants show an increasing tendency to look at pictures and a decreasing tendency to manually explore pictures (Callaghan, Rochat, MacGillivray et al., 2004). The tendency to look at objects was constant and low across development, whereas the tendency to manually explore objects was constant and high. DeLoache, Pierroutsakos, Uttal, Rosengren, and Gottlieb (1998) also reported that infants move from grasping to pointing toward pictures between 9 to 15 months of age. That infants' actions toward pictures switched in the present study between a preponderance of looking following the contemplative stance and a preponderance of manual exploration following a manipulative stance suggests that our manipulation, and not prior knowledge of pictures, was influencing infants' action on pictures. Nevertheless, the effect of prior experience with pictures, and especially with others' attitudes toward pictures, is necessarily confounded in the present study. This is not so in a now-classic study by Hochberg and Brooks (1961), who controlled prior experience with pictures by eliminating any exposure to pictures for the first 19 months of their infants' life. Although these researchers reported that their infant was able to name the items depicted in a range of pictorial symbols once they showed him pictures at 19 months, they did not report what he did with the pictures. There was mention of having to "monitor" the his access to picture books, and "unsuccessful attempts being made to convert the 
test to an interesting game" (pp. 626-627), but it is not possible to discern from their report whether the Hochberg and Brooks infant contemplated or manipulated those pictures. The latter is more likely given the high levels of manipulation of pictures reported for 6- and 9-month-old infants both in the current study and by Callaghan, Rochat, MacGillivray et al. (2004) in their free exploration study. It is also interesting to note that even the 18-month-old infants in the current study were sensitive to the stance adults took toward these symbolic artifacts, regardless of whether that action was conventional. Thus, even older infants appear still to be open to instruction on how to act on pictorial symbols. What we have shown is that modeling referential actions on pictures can be picked up and emulated by infants; what is needed are more naturalistic studies such as Szechter and Liben (2004) to help us to understand exactly how, and indeed whether, the referential nature of pictures is taught to young infants and children.

The actions infants come to take toward pictures after interacting with adults in social situations such as those in the current study may look like the real thing, but their appearance is deceiving. Infants' contemplation of pictures observed here must be considered in light of the many studies that have failed to demonstrate the successful use of pictures as symbols in children younger than 2.5 years (Callaghan, 1999, 2000; Callaghan \& Rankin, 2002; DeLoache, 1991, DeLoache \& Burns, 1994; DeLoache et al., 1996). It is unlikely that the contemplative actions we elicited in these infants helped them overcome the larger conceptual paradox of dual reality at such a tender age and, with such little exposure to communicative exchanges, about the symbolic function of pictures. Callaghan and Rankin (2002) suggest that highlighting the symbol-referent relation in communicative interactions with pictures does not affect picture symbol comprehension until the 3rd year. Nevertheless, we are proposing that acting toward pictures as the others around you act may provide essential firsthand experience that enables toddlers and preschoolers to understand later the referential link inherent in the pictures that others use, much as early modeling of facial expressions may help infants understand later aspects of the self (Meltzoff, 1990; Meltzoff \& Moore, 1999).

Determining the conceptual understanding of symbols in young children is a difficult challenge, but one that must be met if we are to understand how and when children reach this level of understanding. In the context of language, Shaw and Nelson (2002) argued that early word use reflects "use without knowledge" of the symbolic function, knowledge they claimed occurs relatively late in language development. Many researchers (e.g., Bates, Camaioni, \& Volterra, 1975; Halliday, 1979) have demonstrated the occurrence of such protolanguage, a precursor to culturally shared language wherein infants produce idiosyncratic vocalizations and gestures shortly before they produce their first words. Watching infants babble and gesticulate in their unique infant tongues looks for all the world like language but lacks the critical component of shared reference. It is use without knowledge. In the current research, we believe we have tapped into proto-symbolism in the domain of pictorial symbols.

Other research corroborates this suggestion that proto-symbolism does occur in the actions of young infants toward pictures. Infants often "read" picture books, first holding them and babbling in long strings of proto-language and later naming them once when they are producing language. In one study of 18- to 30-month-olds, DeLoache, Uttal, and Pierroutsakos (2000) reported that the strongly held preference for viewing pictures in their canonical orientation that is characteristic of older children and adults was not found until 30 months in their sample. The disregard for canonical orientation of pictures in infancy suggests that infants may not yet have an understanding of the function of pictures even when they may act appropriately toward picture books (i.e., "naming" and "reading" the pictures in the book). Proto-symbolism also occurs in the context of external productions, such as the scribbles of toddlers (Callaghan, 2003). Toddlers often name the scribble marks they produce after the fact, acting as though they intended them to serve as referential artifacts, often after an adult has asked them what they have drawn. Both of these situations are examples of use without knowledge in the pictorial symbol domain, in spite of the iconicity between the form of the early actions (e.g., "reading" picture books, or naming their drawings) and later actions employed by fluent symbol users (e.g., discussing the meaning of an artwork or announcing that one has finished the commissioned portrait).

On the basis of the current findings and prior research, we believe that infants' knowledge of pictorial symbols is limited to the action domain in part because they are still limited in their ability to infer and model the perspective of others. Our findings indicate that infants emulate referential actions toward pictures but do not imitate them. In part, this could be simply due to the complexity of the action sequences we demonstrated, which would not be that interesting. However, we suggest 
that development of the modeling process is a more likely reason for the tendency to emulate. Tomasello and colleagues (Tomasello, 1999; Tomasello et al., 1993) drew a distinction between modeling that precisely mimics the modeled behavior (imitation) and that which only approximates the behavior while it reaches the goal (emulation). In the first case learning is focused on the strategies used by the actor to produce the behavior, and it is those strategies that are reproduced in modeling. In the second case learning is focused on the changes in the environmental conditions, and it is those changes that are reproduced, sometimes by other behavioral means than those that were modeled. Thus, imitation is a more social form of reproductive learning than emulation because it takes into account something about the model (i.e., her specific actions) and not just something about the environment. With these distinctions of reproductive behavior in mind, Rochat and Callaghan (in press) predicted that the developmental trajectory for learning about pictorial symbols through modeling begins with emulation of referential actions in infancy and is followed by imitation in the toddler years. However, there has been little research directly testing this claim (but see Callaghan \& Rochat, 2003, 2004, and Callaghan, Rochat, Lerikos et al., 2004, for studies examining the ability of preschoolers to take the perspective of others in picture symbols tasks). Furthermore, even though infants may either precisely or approximately mimic the actions others take, or the symbols they produce (i.e., words), their actions and symbolic productions do not in themselves constitute evidence of conceptual knowledge of the function of those actions and symbols.

Exactly when the infant can go beyond mere emulation of action toward a tentative inference about the strategy behind the action, which may lead to precise imitation of the stance, is still in need of clarification. Indeed, as mentioned previously, full understanding of the referential nature of pictures may require the ability to infer something about the mental state of the symbolizer, to read his or her communicative intentions (Callaghan \& Rochat, 2003, 2004; Callaghan, Rochat, Lerikos et al., 2004). The literature suggests that the onset of conceptual knowledge of the symbolic function of pictures may not develop until late in the 3rd year (Callaghan, 1999, 2000), whereas more mentalistic understanding may follow even later (Callaghan, Rochat, Lerikos et al., 2004). What the current data indicate is that infants and toddlers may adopt appropriate actions toward pictorial symbols without knowledge of their symbolic status at an earlier age. Clearly, studies that trace the crossover between emulating and imitating referential actions toward pictorial symbols are needed to confirm our interpretation of the developmental trajectory of emulation versus imitation in the context of referential actions on pictorial symbols. So too is it necessary to identify the link we have proposed among infants' emulation of referential actions, their ability to read communicative intentions, and later conceptual understanding. Ideally, these would be longitudinal studies.

As we proposed earlier, there are many more precursor processes, beyond modeling referential actions, that need to be explored in the context of pictorial symbols. Many of these the infant and toddler brings to the communicative arena (e.g., understanding communicative intentions, perceptual discrimination and categorization, analogical reasoning, and a drive to be part of the symbol-minded group), and others the culture delivers through the conventions that are played out in the actions of the already symbol minded (e.g., supportive adults, traditions built over cultural time). Currently, we are investigating how intentional understanding and the knowledge that symbols refer to absent referents influence symbolic development in the visual domain. Future research should also begin to look at the larger cultural context to determine whether scaffolding and other social factors found to be effective in facilitating symbolic development are culturally universal or specific.

\section{References}

Akhtar, N. M., Carpenter, M., \& Tomasello, M. (1996). The role of discourse novelty in children's early word learning. Child Development, 67, 635-645.

Akhtar, N., \& Tomasello, M. (1996). Twenty-four-month old infants learn words for absent objects and actions. British Journal of Developmental Psychology, 14, 79-93.

Baird, J. A., \& Baldwin, D. A. (2001). Making sense of human behavior: Action parsing and intentional inference. In B. F. Malle, L. J. Monthses, \& D. A. Baldwin (Eds.), Intentions and intentionality: Foundations of social cognition (pp. 193-206). Cambridge, MA: MIT Press.

Baldwin, D. A. (1991). Infants' contributions to the achievement of joint reference. Child Development, 62, 875-890.

Baldwin, D. A. (1993). Infants' ability to consult the speaker for clues to word reference. Journal of Child Language, 20, 395-418.

Baldwin, D. A., Baird, J. A., Saylor, M. M., \& Clark, M. A. (2001). Infants parse dynamic action. Child Development, 72, 708-717. 
Baldwin, D. A., \& Moses, L. J. (1996). The ontogeny of social information-gathering. Child Development, 67, 1915-1939.

Bates, E., Camaioni, L., \& Volterra, V. (1975). The acquisition of preformatives prior to speech. Merrill-Palmer Quarterly, 21, 205-224.

Callaghan, T. C. (1999). Early understanding and production of graphic symbols. Child Development, 70, 1314-1324.

Callaghan, T. C. (2000). Factors affecting graphic symbol understanding in the third year: Language, similarity and iconicity. Cognitive Development, 15, 207-236.

Callaghan, T. C. (2003). Nascita e primo sviluppo della rappresentazione grafica. Età Evolutiva, 76, 51-63.

Callaghan, T. C., \& Rankin, M. (2002). Emergence of graphic symbol functioning and the question of domain specificity: A longitudinal training study. Child Development, 73, 359-376.

Callaghan, T. C., \& Rochat, P. (2003). Traces of the artist: Links between children's understanding of visual symbols and theories of mind. British Journal of Developmental Psychology, 21, 415-445.

Callaghan, T. C., \& Rochat, P. (2004). Intention to represent in the drawings of 2- to 5-year-old children. Manuscript submitted for publication.

Callaghan, T. C., Rochat, P., Lerikos, M., MacDougall, D. M., \& Court, R. (2004). Conceptual understanding of pictorial symbols in 2.5- to 7-year-old children. Manuscript submitted for publication.

Callaghan, T. C., Rochat, P., MacGillivray, T., \& MacLellan, C. (2004). Grasping at depicted objects in 6- to 18-montholds: Stimulus and task influences. Manuscript submitted for publication.

Campos, J. J., \& Stenberg, C. G. (1981). Perception, appraisal, and emotion: The onset of social referencing. In M. E. Lamb \& R. Sherrod (Eds.), Infants' social cognition: Empirical and social considerations (pp. 273-314). Hillside, NJ: Erlbaum.

Carpenter, M., Nagell, K., \& Tomasello, M. (1998). Social cognition, joint attention, and communicative competence from 9 to 15 months of age. Monographs of the Society of Research in Child Development (Serial No. 255).

DeLoache, J. S. (1991). Symbolic functioning in very young children: Understanding of pictures and models. Child Development, 62, 736-752.

DeLoache, J. S. (2002). Early development of the use of symbolic artifacts. In U. Goswami (Ed.), Blackwell handbook of childhood cognitive development (pp. 206-226). Malden, MA: Blackwell.

DeLoache, J. S., \& Burns, N. M. (1994). Early understanding of the representational function of pictures. Cognition, 52, 83-110.

DeLoache, J. S., Pierroutsakos, S. L., \& Troseth, G. L. (1996). The three $\mathrm{r}^{\prime} \mathrm{s}$ of pictorial competence. In R. Vasta (Ed.), Annals of child development (Vol. 12, pp. 1-48). London: Kingsley.

DeLoache, J. S., Pierroutsakos, S. L., Uttal, D. H., Rosengren, K. S., \& Gottlieb, A. (1998). Grasping the nature of pictures. Psychological Science, 9, 205-210.
DeLoache, J. S., Uttal, D. H., \& Pierroutsakos, S. L. (2000). What's up? The development of an orientation preference for picture books. Journal of Cognition and Development, 1, 81-95.

Field, T. M., Woodson, R., Greenberg, R., \& Cohen, D. (1982). Discrimination and imitation of facial expressions by neonates. Science, 218, 179-181.

Gergely, G., Bekkering, H., \& Kiraly, I. (2002). Rational imitation in preverbal infants. Nature, 415, 755.

Gergely, G., Nadasdy, Z., Csibra, G., \& Biro, S. (1995). Taking the intentional stance at 12 months of age. Cognition, 56, 165-193.

Halliday, M. A. K. (1979). One child's protolanguage. In M. Bullowa (Ed.), Before speech: The beginning of interpersonal communication (pp. 171-190). Cambridge, England: Cambridge University Press.

Harris, P. L., Kavanaugh, R. D., \& Dowson, L. (1997). The depiction of imaginary transformations: Early comprehension of a symbolic function. Cognitive Development, $12,1-19$.

Hochberg, J., \& Brooks, V. (1961). Pictorial recognition as an unlearned ability: A study of one child's performance. American Journal of Psychology, 75, 624-628.

Kirk, R. (1968). Experimental design: Procedures for the behavioral sciences. Belmont, CA: Brooks/Cole.

Kuhl, P. K., \& Meltzoff, A. N. (1982). The bimodal perception of speech in infancy. Science, 218, 1138-1141.

Liben, L. (1999). Developing an understanding of external spatial representations. In I. E. Sigel (Ed.), Development of mental representation: Theories and applications (pp. 297321). Mahwah, NJ: Erlbaum.

Meltzoff, A. N. (1988). Infant imitation and memory: Ninemonth-olds in immediate and deferred tests. Child Development, $59,217-225$.

Meltzoff, A. M. (1990). Foundations for developing a concept of self: The role of imitation in relating self to other and the value of social mirroring, social modeling, and self practice in infancy. In D. Chichetti \& M. Beeghly (Eds.), The self in transition: Infancy to toddlerhood (pp. 139-164). Chicago: University of Chicago Press.

Meltzoff, A. N. (1995). Understanding the intentions of others: re-enactment of intended acts by 18-month-old children. Developmental Psychology, 31, 838-850.

Meltzoff, A. N., \& Moore, M. K. (1977). Imitation of facial and manual gestures by human neonates. Science, 198, 75-78.

Meltzoff, A. N., \& Moore, M. K. (1989). Imitation in newborn infants: Exploring the range of gestures imitated and the underlying mechanisms. Developmental Psychology, 25, 954-962.

Meltzoff, A. M., \& Moore, M. K. (1999). Persons and representation: Why infant imitation is important for theories of human development. In J. Nadel \& G. Butterworth (Eds.), Imitation in infancy (pp. 9-35). Cambridge, England: Cambridge University Press.

Nadel, J., Guerini, C., Peze, A., \& Rivet, C. (1999). The evolving nature of imitation as a format for communication. In J. Nadel \& G. Butterworth (Eds.), Imitation in infancy (pp. 209-234). New York: Cambridge University Press. 
Perner, J. (1991). Understanding the representational mind. Cambridge, MA: MIT Press.

Piaget, J. (1962). Play, dreams and imitation in childhood. New York: Norton.

Robinson, E. J., Nye, R., \& Thomas, G. V. (1994). Children's conceptions of the relationship between pictures and their referents. Cognitive Development, 9, 165-191.

Rochat, P. (1989). Object manipulation and exploration in two- to five-month-old infants. Developmental Psychology, $25,871-884$.

Rochat, P. (2001). The infant's world. Cambridge, MA: Harvard University Press.

Rochat, P., \& Callaghan, T. C. (in press). What drives symbolic development: The case of pictorial comprehension and production. In L. Namy (Ed.), The development of symbolic use and comprehension. Mahwah, NJ: Erlbaum.

Shaw, L. K., \& Nelson, K. (2002). Developing a socially shared symbolic system. In E. Amsel \& J. P. Byrnes (Eds.), Language, literacy, and cognitive development (pp. 27-58). Mahwah, NJ: Erlbaum.

Sigel, I. E. (1978). The development of pictorial comprehension. In S. Bikkar, B. S. Randhawa, \& W. E. Coffman (Eds.), Visual learning, thinking, and communication (pp. 93-111). New York: Academic Press.

Szechter, L., \& Liben, L. (2004). Parental guidance in preschoolers' understanding of spatial-graphic representations. Child Development, 75, 869-885.

Thomas, G. V., Nye, R., \& Robinson, E. J. (1994). How children view pictures: Children's responses to pictures as things in themselves and as representations of something else. Cognitive Development, 9, 141-144.
Tomasello, M. (1999). The cultural origins of human cognition. Cambridge, MA: Harvard University Press.

Tomasello, M. (2001). Perceiving intentions and learning words in the second year of life. In M. Bowerman \& S. C. Levinson (Eds.), Language acquisition and conceptual development (pp. 132-158). Cambridge, England: Cambridge University Press.

Tomasello, M., \& Akhtar, N. (1995). Two-year-olds use pragmatic cues to differentiate reference to objects and actions. Cognitive Development, 10, $201-224$.

Tomasello, M., \& Barton, M. (1994). Learning words in non-ostensive contexts. Developmental Psychology, 30, $639-650$.

Tomasello, M., \& Farrar, M. (1986). Joint attention and early language. Child Development, 57, 1454-1463.

Tomasello, M., Kruger, A., \& Ratner, H. H. (1993). Cultural learning. Behavioral and Brain Sciences, 16, 495-552.

Troseth, G. L. (2003). TV guide: Two-year-old children learn to use video as a source of information. Developmental Psychology, 39, 140-150.

Wood, D., Bruner, J., \& Ross, G. (1976). The role of tutoring in problem solving. Journal of Child Psychology and Psychiatry, 17, 89-100.

Woodward, A. L. (1999). Infants' ability to distinguish between purposeful and non-purposeful behaviors. Infant Behavior and Development, 22, 145-160.

Woodward, A. L. (2003). Infants' understanding of the link between looker and object. Developmental Science, 6, 297-311.

Woodward, A. L., \& Guajardo, J. J. (2002). Infants' understanding of the point gesture as an object-directed action. Cognitive Development, 17, 1061-1084. 
This document is a scanned copy of a printed document. No warranty is given about the accuracy of the copy. Users should refer to the original published version of the material. 